\author{
CONF-890798--13 \\ J. D. Jorgensen \\ Materials Science Division \\ DE 90002185 \\ Argonne National Laboratory \\ Argonne, IL 60439
}

July 1989

The submitted manuscript has been authored by a contractor of the U.S. Government under contrac No. W-3t-102-ENG-38. Accordingly, the U.S. Covernment retains a nonexdusive, royahy-free license to publith or reproduce the published form of this contribution, or allow others to do so, for U.S. Government purposes.

\title{
DISCLAIMER
}

\begin{abstract}
This report was prepared as an account of work sponsored by an agency of the United States Government. Neither the United States Government nor any agency thereof, nor any of their employes, makes any warranty, express or implied, or assumes any legal liability or responsibility for the accuracy, completeness, or usefulness of any information, apparatus, product, or process disclosed, or represents that its use would not infringe privately owned rights. Reference herein to any specific commercial product, process, or service by trade name, trademark, manufacturer, or otherwise does not necessarily constitute or imply its endorsement, recommendation, or favoring by the United States Government or any agency thercof. The views and opinions of authors expressed herein do not necessarily state or reflect those of the United States Government or any agency thereof.
\end{abstract}

Inivted paper submitted to the 12th AIRAPT and 27th EHPRG International Conference on High Pressure Science and Technology, Paderborn, Germany, 17-21 July, 1989

Proceedings to be published by Gordon and Breech Scientific Publishers

This work is supported by U.S. Department of Energy, Basic Energy Sciences Materials Sciences, under contract \#W-31-109-ENG-38. 
Invited paper submitted to the 12th AIRAPT and 27th EHPRG International Conference on High Pressure Science and Technology, Paderborn, Germany, 17-21 July 1989.

Proceedings to be published by Gordon and Breech Scientific Publishers.

\section{Structural Studies at High Pressure Using Time-of-Flight Neutron Powder Diffraction}

J. D. Jorgensen, Materials Science Division, Argonne National Laboratory, Argonne, IL 60439 USA 


\title{
Structural Studies at High Pressure Using Time-of-Flight Neutron Powder. Diffraction
}

\author{
J. D. Jorgensen \\ Materials Science Division \\ Argonne National Laboratory, Argonne, IL 60439 USA
}

\begin{abstract}
Time-of-flight neutron powder diffraction offers unique capabilities for structural studies at high pressure. Scientific applications have included studies of compression mechanisms, new high-pressure structures, and phase transitions.

Neutron powder diffraction (NPD) techniques have been used for a number of years to study structural properties of samples in high pressure environments. The success of this method largely stems from the high penetrating power of the neutron, allowing a number of different pressure cell designs to be employed. Although many experiments have been done by the constant-wavelength technique on reactor neutron sources, the constant-angle time-of-flight (TOF) technique, used originally at reactors and more recently at pulsed neutron sources, has proven most effective because of the ability to completely mask unwanted scattering from the pressure cell (Jorgensen, 1988). Due to space limitations, this brief review will focus on high-pressure structural studies done by the TOF NPD technique, largely pioneered at Argonne National Laboratory.

Pressure cell designs differ according to the maximum pressure. Two designs are most commonly used (Jorgensen, 1988). Supported aluminum oxide cells take advantage of the high compressive strength of aluminum oxide. A hollow cylinder of aluminum oxide is supported by a steel binding ring assembled such that, at zero sample pressure, the aluminum oxide is under maximum compression. As the sample pressure is increased, the compression in the aluminum oxide decreases, eventually passing through zero. The cell fails when the aluminum oxide reaches it's tensile limit, typically corresponding to a sample pressure of 30-50 kbar depending on cell dimensions and geometry. The other popular design is a relatively standard helium gas pressure cell, typically capable of pressures to about 8 kbar. Gas cells offer the advantages of precise pressure control and measurement, perfectly hydrostatic conditions, and large sample volume.

TOF NPD studies at high pressure have concentrated mainly in three areas: (1) compression mechanisms, (2) determination of structures which exist only at high pressure, and (3) pressure-induced phase transitions. Brief examples which illusirate the strengths of the technique in each area will be discussed.
\end{abstract}


Compression mechanism studies have the goal of understanding the response of individual bond lengths and angles to applied pressure. Such information is important in geophysics and also in understanding the mechanical properties of technologically useful materials. Perhaps the bestknown example of such work is the study of compression mechanisms in the isostructural alpha-quartz forms of $\mathrm{SiO}_{2}$ and $\mathrm{GeO}_{2}$. (Jorgensen, 1978). In $\mathrm{SiO}_{2}$, compression results from a cooperative rotation of nearly rigid $\mathrm{SiO}_{4}$ tetrahedra, while in $\mathrm{GeO}_{2}$ the analogous rotation has already proceeded so far at ambient pressure that compression must proceed by distorting the tetrahedral angles. Bond-length changes are very small in both cases. This behavior forms the basis for understanding compression in a wide range of ceramics, such as $\mathrm{Si}_{3} \mathrm{~N}_{4}$ and $\mathrm{Si}_{2} \mathrm{~N}_{2} \mathrm{O}$ (Cartz and Jorgensen, 1981), and minerals with framework structures.

New structures determined recently at high pressure include $\mathrm{KNO}_{3}-\mathrm{TV}$ at $3.6 \mathrm{kbar}$ (Worlton et al., 1986) and $\mathrm{ND}_{4} \mathrm{~F}-\mathrm{II}$ at $4.7 \mathrm{kbar}$ (Lawson et al., 1989). In both cases, TOF NPD data taken in a helium gas cell were of high enough quality to allow the unknown structures to be indexed and the space groups determined. Full structure refinements were then done by the Rietveld method. Fig. 1 shows the Rietveld refinement profile for a mixure of $\mathrm{KNO}_{3}-\mathrm{II}$ and $\mathrm{KNO}_{3}-\mathrm{IV}$ at $3.06 \mathrm{kbar}$, where, because the transformation is first order, the two phases coexist even though the pressure is perfectly hydrostatic (Worlton, Jorgensen, and Kleb, unpublished). $\mathrm{ND}_{4} \mathrm{~F}$-II with 24 molecules in a $1024 \dot{A}^{3}$ hexagonal unit cell is one of the most complex

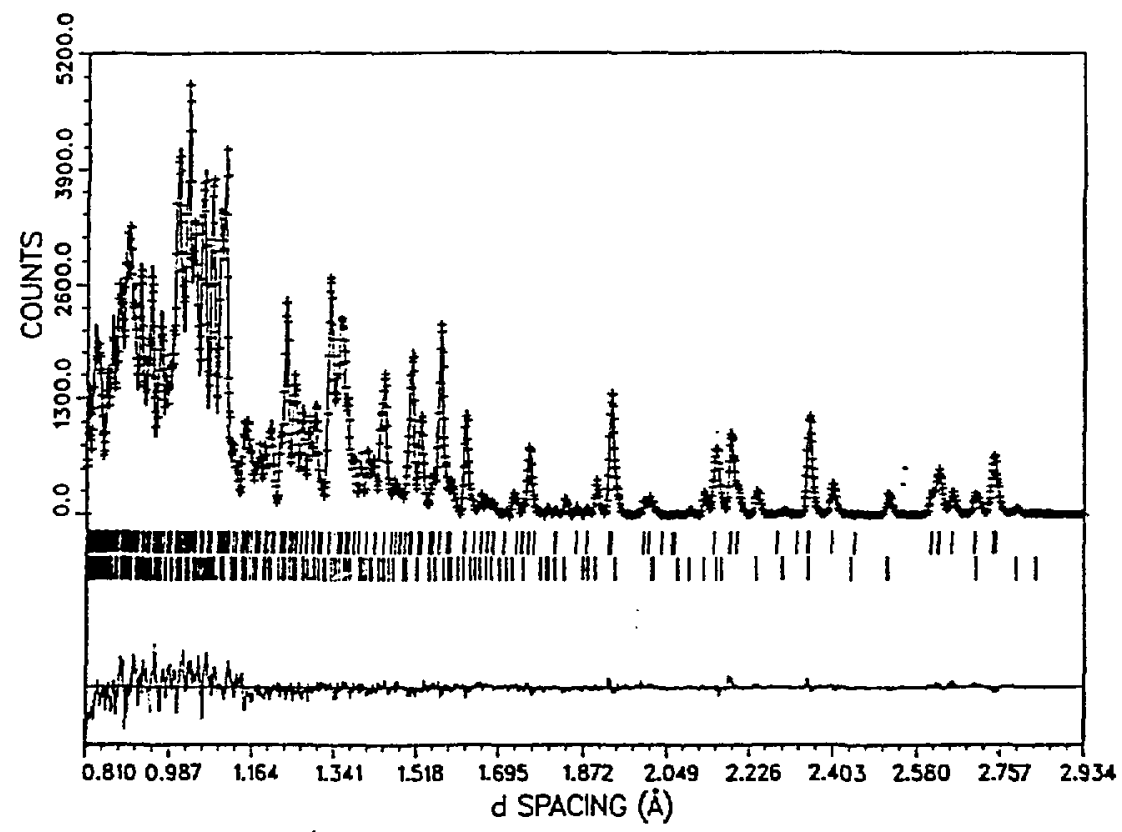

Fig. 1. Rietveld refinement profile for a mixture of $\mathrm{KNO}_{3}-\mathrm{II}$ and $\mathrm{KNO}_{3}-\mathrm{IV}$ at $3.06 \mathrm{kbar}$ and $295 \mathrm{~K}$. Tick marks below the plot mark the positions of allowed peaks for the two phases. 
structures to be solved from high pressure data. Other well-known structural determinations include sudies of $\mathrm{D}_{2} \mathrm{O}$ ice- $\mathrm{V \Pi}$ at $26 \mathrm{kbar}$ (Jorgensen and Worlton, 1985) and ice-VIII at $28 \mathrm{kbar}$ (Jorgensen et al., 1984) for which the unit cells were known from $\mathrm{x}$-ray studies, but the positions of the light $\mathrm{D}$ atoms could only be determined by neutron diffraction.

Studies of phase transitions have included electronic transitions such as the Lifshitz transition in InBi (Jorgensen and Clark, 1980), Martensitic transformations as in lithium metal (Smith, Berliner, and Jorgensen, 1989), and soft-mode transitions as in $\mathrm{NiF}_{2}$ (Jorgensen, Worlton and Jamieson, 1978) and $\mathrm{ReO}_{3}$ (Jorgensen et al., 1986). The studies of soft-mode transitions offer the best example of the unique capability for neutron powder diffraction to give accurate Bragg intensities from which structural parameters, such as bond lengths and angles, can be determined. Thus, for both $\mathrm{NiF}_{2}$ and $\mathrm{ReO}_{3}$ it was possible to accurately measure the pressure dependence of the appropriate order parameters for the transitions, e.g., the rotation angle of $\mathrm{ReO}_{6}$ octahedra in the case of $\mathrm{ReO}_{3}$.

\section{ACKNOWLEDGEMENTS}

This work is supported by the U. S. Dept. of Energy, Basic Energy Sciences - Materials Sciences, under contract No. W-31-109-ENG-38. The author also wishes to thank numerous colleagues, named in the references, with whom he has collaborated.

\section{REFERENCES}

L. Cartz and J. D. Jorgensen, J. Appl. Phys. 52, 236 (1981).

J. D. Jorgensen, J. Appl. Phys. 49, 5473 (1978).

J. D. Jorgensen, in Chemical Crystallography with Pulsed Neutrons and Synchrotron X-ravs, edited by M. A. Carrondo and G. A. Jeffrey (NATO ASI Series C: Vol. 22, D. Reidel, Dordrecht, Holland, 1988) p. 159.

J. D. Jorgensen, R. A. Beyerlein, N. Watanabe, and T. G. Worlton, J. Chem. Phys. 81, 3211 (1984).

J. D. Jorgensen and J. B. Clark, Phys. Rev. B 22, 6149 (1980).

J. D. Jorgensen and T. G. Woriton, J. Chem. Phys. 83, 329 (1985).

J. D. Jorgensen, T. G. Worlton, and J. C. Jamieson, Phys. Rev. B 17 , 2212 (1978).

J.-E. Jorgensen, J. D. Jorgensen, B. Batlogg, J. P. Remeika, and J. D. Axe, Phys. Rev. B 33, 4793 (1986).

A. C. Lawson, R. B. Roof, J. D. Jorgensen, B. Morosin, and J. E. Schirber, Acta Cryst. B45, 212 (1989).

H. G. Smith, R. Berliner, and J. D. Jorgensen, Physica B 156\&157, 53 (1989).

T. G. Worlton, D. L. Decker, J. D. Jorgensen, and R. Kleb, Physica B 136,503 (1986). 